\title{
Relações Públicas e sua função dialógica
}

\author{
Public Relations and their dialogical function
}

\section{Las Relaciones Públicess y su función dialógica}

\section{Luiz Alberto de Farias}

- Doutor em Integração da América Latina pela Universidade de São Paulo

- Mestre em Comunicação e Mercado pela Faculdade Cásper Líbero

- Graduado em Jornalismo pela Faculdade Cásper Líbero e em Relações Públicas pela Universidade Cruzeiro do Sul (Unicsul)

- Professor titular da Faculdade Cásper Líbero e professor da ECA-USP

- Presidente da Associação Brasileira de Relações Públicas - Seção de São Paulo (ABRP-SP)

- Editor de Organicom - Revista Brasileira de Comunicação Organizacional e Relações Públicas

- Autor de A literatura de relações públicas: produção, consumo e perspectivas (2004)

- Organizador de Aprender na prática: experiências de ensino e aprendizagem (2007)

- Autor de diversos capítulos de livros

- lafarias@usp.br 
Este artigo trata das Relações Públicas considerando-as um campo instituído e que tem como diferencial a função dialógica, responsável pela consolidação de relacionamentos entre as organizações e seus públicos. Utilizam-se os conceitos de campo e cultura para que se entenda o porquê do diferencial da área como intérprete e mediadora de situações de disputa e de conflitos. Como panorama para visualização do atual cenário, resgata-se o papel da Associação Brasileira de Relações Públicas (ABRP) como entidade que contribuiu para a institucionalização desse campo de conhecimento e de prática profissional.

PALAVRAS-CHAVE: RELAÇÕES PÚBLICAS • FUNÇÃO DIALÓGICA

\section{Abstract}

This article addresses Public Relations considering them to be an established field that has dialogical function as a differential, responsible for consolidation of relationships between organizations and their publics. It uses the concepts of field and of culture for an understanding of the reason for the area's differential as an interpreter and mediator of situations of dispute and conflict. With the purpose of visualizing the current scenario, one mentions the role of the Associação Brasileira de Relações Públicas (ABRP - Brazilian Public Relations Association), as the entity that contributed to the institutionalization of this field of knowledge and of professional practice.

KEYWORDS: PUBLIC RELATIONS • DIALOGICAL FUNCTION

Resumen

Se abordan las Relaciones Públicas como un campo instituido que tiene como diferencial la función dialógica, responsable de la consolidación de las relaciones entre las organizaciones y sus públicos. Se utilizan los conceptos de campo y cultura para ofrecer una comprensión de por qué el área presenta diferenciales como intérprete y mediadora de situaciones de disputa y de conflictos. Como panorama para la visualización del actual escenario, se rescata el papel de la Associação Brasileira de Relações Públicas (ABRP) como entidad que contribuyó a la institucionalización de este campo de conocimiento y de la práctica profesional correspondiente.

PALABRAS CLAVE: RELACIONES PÚBLICAS • FUNCIÓN DIALÓGICA 
A s Relações Públicas sempre tiveram de lidar com questões polêmicas e estas continuam a perpassar o seu caminho. Do ponto de vista conceitual o que hoje talvez mais gere discussão é a sua posição em relação à chamada Comunicação Organizacional ou Comunicação Empresarial, que no Brasil, muito comumente, é vista como equivalente às Relações Públicas e muitas vezes apresente um significado similar ao que estas têm.

\section{Espaços de disputa}

Terminologias à parte, as Relações Públicas são a atividade que corresponde às ações concretas e/ou simbólicas de comunicação no âmbito das organizações (ecossistemas sociais), independentemente de nesse espaço se fazer presente uma grande diversidade de profissionais vindos de outras habilitações da Comunicação ou mesmo de formações diferentes, mas que, de algum modo, acrescentam debate/ qualidade/ diversidade à área.

As Relações Públicas são um campo de atividade profissional e intelectual, com densa história, práticas consolidadas, substância teórica e massa crítica. De acordo com Bourdieu (2003), campo pode ser definido como uma configuração relacional de forças em disputa pelo que é considerado importante nesse mesmo campo. As Relações Públicas, mesmo sendo uma área profissionalmente regulamentada1, vivem em um território no qual coexistem diversos outros interesses que levam à presença, nele, de profissionais, terminologias e forças ora conflitantes ora complementares. O espaço no qual ocorrem essas disputas acaba por ser positivo, pois pode privilegiar a ampliação da qualidade do que se oferta por meio desses concorrentes, mesmo que estes tenham por objetivo estabelecer o monopólio sobre o tipo específico de capital pertinente ao campo.

A disputa, por outro lado, também gera a possibilidade de diálogo e de interação. Nesse aspecto pode-se pontuar a visão habermasiana de "ação comunicativa”, a partir da qual

a interação de ao menos dois sujeitos capazes de linguagem e de ação que (seja com meios verbais ou com meios extraverbais) entabulem uma relação interpessoal. Os atores buscam entender-se sobre uma situação de ação e com isso suas ações (HABERMAS, 1987, p. 124).

Assim, as Relações Públicas representam espaços de disputa ou as representações das disputas por/em espaços, seja pelo aspecto da posse simbólica de

1 Alguns têm restrições à regulamentação pelo período de sua efetivação ou por entenderem que ela seja ultrapassada, talvez devendo ser restrita somente a determinadas categorias profissionais - as ditas clássicas. Tudo não passa de discussão vazia, pois a regulamentação é fato e o período no qual ocorreu não a desmerece se for somente essa a crítica. A defesa de regulamentação, todavia, não está aqui presente, apenas a constatação da existência de uma lei, mesmo que já há muito Ruy Barbosa tenha dito "a lei, ora a lei!", sabedor da cultura de nosso País. 
seu campo profissional, seja pelo desenvolvimento de seu campo intelectual e acadêmico e, mais, pela representação simbólica das interpretações que acontecem nos espaços intra-, inter- e transorganizacionais. Nesses ambientes os sujeitos são enredados por teias de significados tecidas por eles mesmos (GEERTZ, 1989). Segundo Habermas (1987), a interação se dá por meio da possibilidade de negociação e de criação de consenso.

Acima de tudo, o sentido das Relações Públicas, então, se dá por meio da clareza de sua presença-ação e da demanda por elas em situações que envolvam conflitos, vistos como rupturas entre as mensagens e a interpretação de seus significados. Dessa maneira, indivíduos, organizações ou quaisquer outras naturezas de representações de interesse - sujeitos construtores e resultados da sociedade - são traduzidos por cada cultura, que é elemento "gerador de estruturalidade: cria à volta do homem uma sociosfera que, da mesma maneira que a biosfera, torna possível a vida [...] de relação", conforme dizem Iuri Lotman e Boris Uspenskii (apud MACHADO, 2003, p. 39). E, segundo Bakhtin (1982, p. 352), "no encontro dialógico as duas culturas não se fundem nem se mesclam, cada uma conserva sua unidade, sua totalidade aberta, porém ambas se enriquecem mutuamente”.

As Relações Públicas apresentam, assim, uma função dialógica, por meio da qual criam campo de pensamento que permite o equilíbrio entre interesses por meio de interpretação de significados e da ação pontual ou permanente de integração entre acontecimentos e as suas teias de representações nos espaços simbólicos de disputa e de conflito e, possivelmente, de encontro e diálogo.

\section{A ABRP e o processo de relações públicas}

A partir de 1954, com a fundação, em São Paulo, da Associação Brasileira de Relações Públicas, a consolidação da área de fato ganhou corpo. A entidade, que se espalhou para outras regiões do País, conseguiu, por meio de inúmeras atividades, oferecer um lugar de fala aos praticantes e pesquisadores do tema. Foi também a partir dela ou de alguns de seus integrantes que o movimento pela regulamentação da profissão ganhou estímulo. Com a legislação estabelecida para a área, a ABRP passou a compartilhar o espaço de trabalho com os conselhos federal e regionais criados mais tarde, mas mantendo ainda clara a sua própria missão. Além disso, coube a ela a criação, em 1982, por meio da seção de São Paulo, do Concurso Universitário de Monografias e Projetos Experimentais, que, denominado oficialmente "Prêmio ABRP - Concurso Universitário de Monografias e Projetos Experimentais” desde sua 25a. edição (2007), hoje percorre a terceira década de existência, sempre promovendo a integração e estimulando o fortalecimento da pesquisa.

Se a área pode ser considerada em processo, podemos perceber que a ABRP, ao longo desses 55 anos, teve um papel significativo em seu desenvolvimento e 
na manutenção de sua solidez. Pelos quadros da entidade passou a maioria dos grandes nomes de Relações Públicas do País, tanto dos que atuam ou atuaram principalmente no mercado quanto dos que transitam predominantemente no âmbito acadêmico.

A ABRP, assim, tem-se mostrado como um espaço de encontro, de diversidade, de crescimento para a profissão e para os que nela militam.

\section{Trânsito histórico-conceitual}

A "criação" da área de Relações Públicas, em 1906, nos Estados Unidos, se associa diretamente à Assessoria de Imprensa. No Brasil, por outro lado, seu início foi fortemente atrelado à área de Cerimonial, o que de certo modo ainda persiste, pois a organização de eventos continua tendo grande expressão no portfólio de Relações Públicas. São duas atividades que podem traduzir a função dialógica, mas não encerram o todo de possibilidades das Relações Públicas.

Talvez por isso, em nosso País como nos Estados Unidos, haja uma certa vinculação forte a esta ou àquela estratégia, o que de fato é um equívoco, pois ambas devem fazer parte de um planejamento que interprete o conjunto de necessidades e não se constituir em fatores isolados. Nesses pouco mais de cem anos, as Relações Públicas conseguiram consolidar sua conceituação por meio de trabalhos de autores de origens diversas mas muito sólidos, deitando por terra problemas como esses, de atribuição restrita. Elas receberam contribuições que lhe deram o perfil que hoje atrai inúmeros profissionais, de diferentes formações, para dedicar-se a seu estudo ou à sua prática.

Ainda que percebamos um certo hiato entre o início de sua prática "oficial", em 1906, e os primeiros trabalhos significativos, podemos entender que as Relações Públicas ganharam forma de modo equilibrado e processual, gerando uma realidade que expressa, particularmente no Brasil, uma forte massa crítica em termos de pesquisa e de atuação no mercado de trabalho.

\section{Espaços em disputa}

Embora tenhamos iniciado estas reflexões falando de disputa de espaços, vale lembrar que esta é sempre muito salutar, a partir do momento em que exista a ética como referência, o que nos parece ser o caso.

O crescimento da demanda pela atividade de Relações Públicas fez com que muitos profissionais passassem a desejar alterações no cenário legal. Se neste ano 2009 a atividade de Jornalismo - tão próxima às Relações Públicas, em especial pela atuação no mercado de trabalho - passou por profundas transformações com o fim da Lei de Imprensa e a queda da exigência do diploma para 
a sua prática, a área de Relações Públicas - mesmo que em algumas situações travestida com outros nomes - parece ganhar espaço.

Processos judiciais, aparições negativas na imprensa, greves, movimentos difamatórios, multiplicação do poder das mídias sociais, esses e inúmeros outros fatores podem ser trabalhados, entendidos, interpretados e mediados por Relações Públicas. Os sujeitos individuais e coletivos tecem e vêem tecidos os significados sociais: têm nas Relações Públicas um agente de mediação, de interpretação e de reinterpretação, pois não se sujeitam a serem moldados pelo entorno, pelo contexto.

A atuação de Relações Públicas - como se defende atualmente - é estratégica. É claro que não se podem deixar de lado as ações pontuais, operacionais, sem as quais a estratégia não se efetiva, mas pensar em termos de médio e longo prazos se torna cada dia mais exigível, pois os resultados organizacionais ideais passam por conceitos que não podem ficar restritos somente ao plano da comunicação ou ao do saber-fazer. Talvez por isso as Relações Públicas sempre tiveram certa facilidade em compreender as necessidades das empresas. Precisam apenas não deixar de perceber as inúmeras transformações que estão - e, parece, sempre estarão - em curso.

\section{Referências}

BAKHTIN, Mikail. Estética de la creación verbal. Trad. de Tatiana Bubnova. México: Siglo 21, 1982.

BOURDIEU, Pierre. 0 poder simbólico. Trad. de Fernando Tomaz. 6. ed. Rio de Janeiro: Bertrand Brasil, 2003.

GEERTZ, Clifford. A interpretação das culturas. Trad. de Fanny WrobeL Rio de Janeiro: LTC, 1989.

HABERMAS, Jürgen. Teoría de la acción comunicativa: nacionalidad de la acción y racionalización social. Trad. de Manuel Jiménez R. Madrid: Taurus, 1987.

MACHADO, Irene. Escola de semiótica: a experiência de Tártu-Moscou para o estudo da cultura. São Paulo: Ateliê Editorial / Fapesp, 2003. 